\title{
In the limelight
}

\author{
Photonics research features heavily in the 2008 Prince of Asturias Awards, where its role in \\ benefiting the environment and combating poverty is celebrated.
}

It's always satisfying and motivating to have your work recognized, be it in the form of a publication, a funding grant or an invitation to speak at a conference. Needless to say, it's even more rewarding when your research is selected for a prestigious international award that celebrates your work's benefit to mankind.

As we go to press, several scientists involved in photonics research have received this honour with the announcement of the recipients of the 2008 Prince of Asturias Award for Technical and Scientific Research ${ }^{1}$. This year's award was announced on 4 June, and photonics featured heavily with Shuji Nakamura from the University of California, Santa Barbara, Tobin Marks from Northwestern University, George Whitesides from Harvard University and Sumio Iijima from NEC all receiving the award. A fifth recipient was Robert Langer from the Massachusetts Institute of Technology, whose work on pharmaceuticals was recognized.

To those who are not familiar with the Prince of Asturias Awards, they were established in 1981 by the Prince of Asturias Foundation in Oviedo, Spain. Eight awards are issued annually with the intention of recognizing achievements that bestow the utmost benefit to mankind.

In a similar fashion to the Nobel Prize, the Prince of Asturias awards acknowledge international scientific, technical, cultural, social and humanitarian work carried out by individuals, groups or organizations. The categories for the eight awards are communication and humanities, social sciences, arts, letters, scientific and technical research, international cooperation, concord and sports.

The 2008 Technical and Scientific Research award was granted to the five scientists named above to celebrate their great contributions to the protection of the

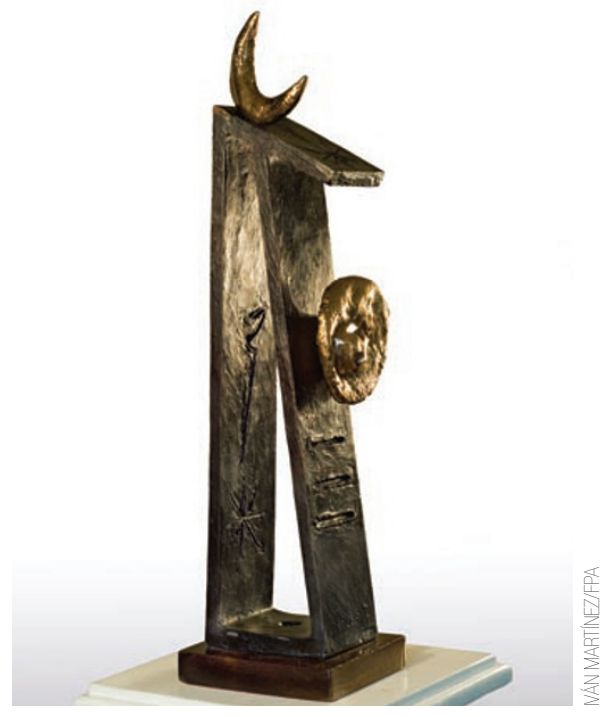

environment, energy saving and combating poverty, through the creation and use of new sources of clean, low-cost energy. Browsing through their achievements, it is worthy of mention that four of the awardees have made a significant contribution to the field of photonics.

Shuji Nakamura's pioneering research on short-wavelength gallium nitride LEDs and lasers helped create white LEDs. Such LEDs are an attractive alternative to incandescent bulbs as an efficient, longlifetime source of light that can be powered by batteries and used in underdeveloped areas that are not covered by a gridbased power supply ${ }^{2}$. His research also contributed greatly to the development of UV LEDs, which can be used as a highly convenient means to sterilize drinking water. Needless to say the ability to provide clean drinking water and light will greatly improve life and health conditions for many millions of people living in developing countries.
Tobin Marks has developed processes for fabricating recyclable, environmentally friendly plastics, as well as devices based on flexible, low-cost organic materials, such as prototype organic photovoltaic solar cells. As part of his research, he has also succeeded in making organic transistors and organic LEDs. Organic LEDs have recently started to find their way into electronic devices such as PDAs (personal digital assistants) and mobile phones, as well as the emerging flexible display technology known as electronic paper.

George Whitesides shares the honour of the award as a result of the fabrication techniques he developed for producing nanoscale materials, including a method called soft lithography. It is worth noting that Whitesides is also an active researcher in the area of optofluidics, in which he builds devices that bring together flowing liquids and light beams in devices that can be reconfigured or tuned in real time $e^{3,4}$.

Sumio Iijima discovered carbon nanotubes in 1991. It has been reported that they may be useful for safe storage of hydrogen, a future fuel. Carbon nanotubes are also being exploited for optoelectronics and photonics applications because of their unusual electrical and optical properties ${ }^{5}$.

The awards recognize the work of these scientists for their great contributions to the sustainable development of the planet and the fight against poverty, highlighting the vital role of photonics towards achieving a cleaner and more energy-efficient lifestyle for today's society.

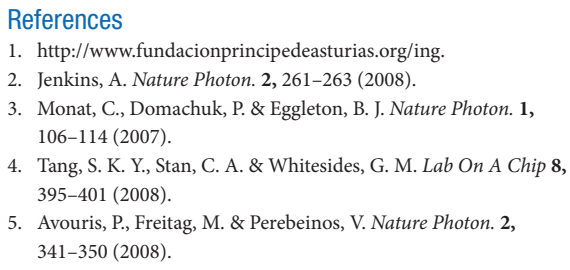

